\title{
Force-Modulated Reductive Elimination from Platinum(II) Diaryl Complexes
}

\author{
Yichen Yu, a Liqi Wang, ${ }^{a}$ Chengxu Wang, ${ }^{\mathrm{b}}$ Yancong Tian, ${ }^{\mathrm{b}}$ Roman Boulatov, ${ }^{* \mathrm{~b}}$ Ross A. Widenhoefer \\ ${ }^{* a}$ and Stephen L. Craig *a \\ Coupled mechanical forces are known to drive a range of covalent chemical reactions, but the interplay of mechanical force \\ applied to a spectator ligand and transition metal reactivity is relatively unexplored. Here we report the effect of \\ mechanical force on the rate of $\mathrm{C}\left(\mathrm{sp}^{2}\right)-\mathrm{C}\left(\mathrm{sp}^{2}\right)$ reductive elimination from platinum(II) diaryl complexes containing \\ macrocyclic bis(phosphine) force probe ligands. Compressive forces decreased the rate of reductive elimination whereas \\ extension forces increased the rate of reductive elimination relative to the strain-free MeOBiphep complex with a 3.4-fold \\ change in rate over a $\sim 290 \mathrm{pN}$ range of restoring forces. The natural bite angle of the free ligand changes with force, but \\ ${ }^{31} \mathrm{P} N M R$ analysis strongly suggests no significant force-induced perturbation of the ground state geometry of the (P-P)PtAr2 \\ complexes. Rather, the force/rate behavior observed across this range of forces (from ca. $65 \mathrm{pN}$ in compression to $>200$ \\ $\mathrm{pN}$ in extension) for reductive elimination is attributed to the coupling of force to the elongation of the $\mathrm{O} \cdots \mathrm{O}$ distance in the \\ transition state for reductive elimination. The results suggest opportunities to experimentally map geometry changes \\ associated with reactions in transition metal complexes and potential strat-egies for force-modulated catalysis.
}

\section{Introduction}

Over the last decade or so, coupled mechanical forces have been used to drive a range of targeted covalent responses in isolated polymers and in bulk polymeric materials (covalent polymer mechanochemistry). ${ }^{1,} \quad 2$ Mechanochemical strategies continue to evolve, including in very recent years their use in biasing and probing reaction pathways, 3,4 the release of small molecules and protons, $, 5,6$ stress reporting, ${ }^{7-11}$ stress strengthening, 12, 13 degradable polymers, ${ }^{14,15}$ and fundamental studies of polymer behavior under load. ${ }^{16}$ In organic reactions, mechanochemical coupling has been investigated in simple bond dissociation reactions ${ }^{17-19}$ and in a wide variety of reaction classes with respect to regiochemistry, ${ }^{20-24}$ orbital symmetry, ${ }^{20,} 25-27$ stereochemistry, 28, 29 supramolecular architecture, ${ }^{30-32}$ dynamic effects, ${ }^{33}, 34$ and the alignment and/or loading of scissile bonds with applied tension. ${ }^{35,} 36$ Unlike their organic counterparts, however, mechanochemical reactions in organometallic complexes have been focused almost entirely on the direct, forced dissociation of a ligand, including some of the earliest examples of polymer mechanochemistry, ${ }^{37-40}$ the release of latent catalysts, ${ }^{41-43}$ and as a means of generating colorimetric responses.44-47 In an emerging complementary strategy, a force applied to an intact ligand scaffold tunes reactivity at the coordinated metal center. In particular, force applied to a chiral ligand was shown to influence the enantioselectivity of enantioselective Heck arylations and Trost allylic alkylations. ${ }^{48}$

Because ligand structure so directly impacts the reactivity of organometallic complexes, mechanically coupled ligands offer the potential to externally regulate organometallic reactivity, if fundamental structure- reactivity relationships can be established. The use of force would complement other strategies for externally triggered reactivity. ${ }^{49-53}$ We therefore sought to extend the study of force-coupled ligands to their use in elementary transformations that occur within a structurally welldefined transition metal complex for which the mechanism and reactivity is well characterized in the context of forcefree reactions. Toward these objectives, we have performed chemomechanical analysis ${ }^{54}$ of $\mathrm{C}\left(\mathrm{sp}^{2}\right)-\mathrm{C}\left(\mathrm{sp}^{2}\right)$ reductive elimination from diaryl platinum complexes containing macrocyclic bisphosphine molecular force probe ligands. Reductive elimination represents one of the most important carbon-carbon bond forming processes in cross-coupling reactions, ${ }^{55}$ often closing catalytic cycles initiated by oxidative addition. Platinum(II) diaryl complexes were targeted specifically owing to their stability, ${ }^{56}$ which allows for kinetic analysis at convenient temperatures from isolable complexes and because reductive elimination occurs via a concerted, unimolecular pathway. ${ }^{56-62}$

Our approach is to couple the platinum(II) diaryl complexes to an applied force employing the force probe ligands Z/E(m,n) $(m, n=2,2 ; 2,3 ; 3,3)$, which comprise a stiff stilbene $\left(1,1^{\prime}\right.$-biindane) photoswitch ${ }^{63}$ tethered to a biaryl bisphosphine moiety (Fig. 1). Depending on the tether lengths, these ligands generate compressive forces of up to $65 \mathrm{pN}[\mathrm{Z}(2,2)]$ and extension forces of $>200 \mathrm{pN}[\mathrm{E}(2,2)]$ at the biphen $\mathrm{O} \cdots \mathrm{O}_{\text {biphen }}$ coordinate of the ligand, without perturbation of the electron donor properties of the phosphine. Previous studies on a mechanically coupled electrocyclic ring opening have shown that the effect of force applied intramolecularly by the macrocyclic force probe is effectively equivalent to that of the same force applied externally, for example by the tension in a strained polymer strand. ${ }^{64-67}$ The force probe ligands therefore provide a 
convenient method through which to deliver a single, specific force to metal complexes under conditions that allow their reactivity to be studied using conventional spectroscopic methods, but that also provide insights into how reactivity would be influenced by forces experienced, e.g., in a deformable solid support.
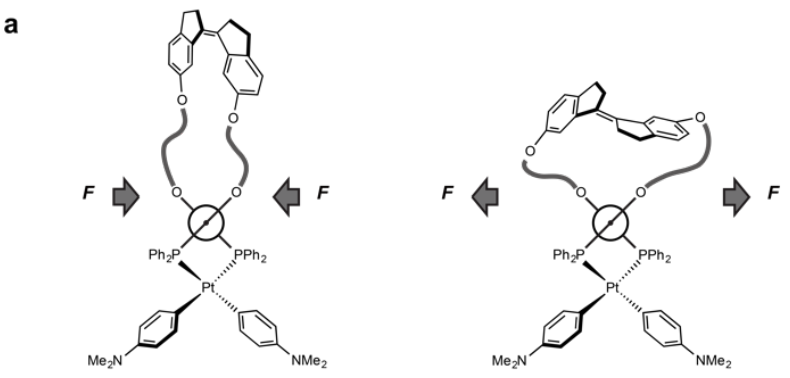

b

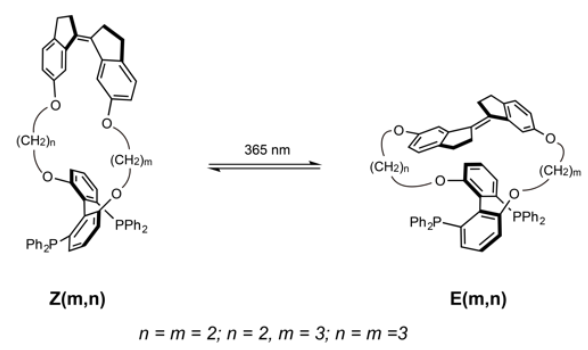

Fig. 1 (a) Schematic representation of the diaryl platinum complexes containing $\mathrm{Z}$ and $\mathrm{E}$ force probe ligands leading to compression or extension forces, respectively, applied to the biaryl backbone. (b) Irradiation of Z-force probe ligands generates a photostationary mixture of Zmacrocycles and an E analog, which were separated chromatographically.

\section{Results and Discussion}

Platinum diaryl bis(phosphine) complexes (P-P)PtAr 2 $\left(\mathrm{Ar}=4-\mathrm{C}_{6} \mathrm{H}_{4} \mathrm{NMe}_{2} ; \quad \mathrm{P}-\mathrm{P}=\right.$ force probe ligand $)$ were synthesized in two steps from the reaction of force probe ligand with (COD) $\mathrm{PtCl}_{2}$ (COD = 1,5-cyclooctandiene) to form dichloride complexes (P-P) $\mathrm{PtCl}_{2}$ followed by transmetallation with 4-dimethylaminophenyl magnesium bromide (Scheme 1). The stiff-stilbene of the platinum dichloride complex of the most extended $E(2,2)$ ligand isomerized to the $\mathrm{Z}(2,2)$ analog within $10 \mathrm{~min}$ at room temperature, which precluded generation of the platinum diaryl complex containing the $E(2,2)$ ligand.

$$
\succ_{P}^{\prime} \quad 85^{\circ} \mathrm{C}
$$

Scheme 1 Synthesis and reductive elimination of diaryl platinum bisphosphine complexes containing force probe ligands. $\quad \mathrm{COD}=$ cyclooctadiene; $\quad \mathrm{DBA}=$ dibenzylideneacetone; $\mathrm{Ar}=4-\mathrm{C}_{6} \mathrm{H}_{4} \mathrm{NMe}_{2}$.

The platinum dichloride and diaryl force probe complexes were fully characterized in solution by ${ }^{1} \mathrm{H}$ and ${ }^{31} \mathrm{P}$ NMR spectroscopy. Importantly, the one-bond platinumphosphorous coupling constants $\left(1_{\mathrm{P}-\mathrm{Pt}}\right)$ for both the platinum dichloride $\left({ }^{1} \mathrm{~J}-\mathrm{Pt}=3645-3671 \mathrm{~Hz}\right)$ and platinum diaryl complexes $\left({ }^{1} \mathrm{P}_{\mathrm{P}-\mathrm{Pt}}=1763-1773 \mathrm{~Hz}\right)$ fell within a narrow range for each series of compounds. The one-bond platinum-phosphorous coupling constant of electronically and sterically homologous bis(phosphine) platinum complexes is highly sensitive to perturbation of ligand geometry. ${ }^{68-70}$ For example, ${ }^{1} \mathrm{JP}_{\mathrm{P}-\mathrm{Pt}}$ for the structurally characterized platinum dichloride complexes $\left[\mathrm{Ph}_{2} \mathrm{P}\left(\mathrm{CH}_{2}\right)_{x} \mathrm{PPh}_{2}\right] \mathrm{PtCl}_{2}(\mathrm{X}=3-5)$ increased by $>230 \mathrm{~Hz}$ with a $\sim 12^{\circ}$ increase in the $\mathrm{P}-\mathrm{Pt}-\mathrm{P}$ bond angle (approximately 19 $\left.\mathrm{Hz} /{ }^{\circ}\right) .{ }^{69}, 70$ This analysis strongly suggests that the geometries of the primary coordination spheres of Pt in all 5 complexes of the series are very similar regardless of the force exerted on the biphenyl moiety by stiff stilbene.

Solutions of $(\mathrm{P}-\mathrm{P}) \mathrm{PtAr}_{2}(\mathrm{P}-\mathrm{P}=$ force probe ligand; 16 $\mathrm{mM}$ ) and dibenzylidene acetone (DBA; 1 equiv) in toluene$d_{8}$ were heated at $85^{\circ} \mathrm{C}$ and analyzed periodically by ${ }^{1} \mathrm{H}$ NMR spectroscopy (Scheme 1). In each case, the disappearance of (P-P)PtAr 2 obeyed first-order kinetics to $\geq 3$ half-lives to form 4,4'-bis(dimethylamino)-1,1'diphenyl and (P$\mathrm{P}) \mathrm{Pt}(\mathrm{DBA})$ as the exclusive organic and organometallic product, respectively (Fig. 2; Table 1). DBA was employed as a trapping ligand to prevent secondary decomposition of the $(\mathrm{P}-\mathrm{P}) \mathrm{Pt}(0)$ species released via reductive elimination. ${ }^{56-}$ 62 The rate of reductive elimination decreased by a factor of 3.4 in the order $\mathrm{E}(2,3)>\mathrm{E}(3,3)>\mathrm{MeOBiphep}>\mathrm{Z}(3,3)>\mathrm{Z}(2,2)$.

Table 1 First-order rate constants for the reductive elimination of ( $P$ P) $\mathrm{PtAr}_{2}$ complexes in toluene- $d_{8}$ at $85^{\circ} \mathrm{C}$.

\begin{tabular}{|c|c|c|c|}
\hline entry & $(\mathrm{P}-\mathrm{P})$ & restoring & \multirow[t]{2}{*}{$\left(10^{5}\right) k$} \\
\hline & & force $(\mathrm{pN})$ & \\
\hline 1 & $\mathrm{Z}(2,2)$ & -65 & $5.8 \pm 0.1^{a}$ \\
\hline \multirow[t]{2}{*}{2} & $\mathrm{Z}(3,3)$ & -3 & 5.89 \\
\hline & & & $0.05^{b}$ \\
\hline 3 & MeOBiphe & 0 & 6.92 \\
\hline \multicolumn{2}{|r|}{ 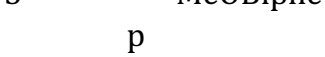 } & & 0.05 \\
\hline 4 & $E(3,3)$ & 130 & $14.8 \pm 0.2^{b}$ \\
\hline 5 & $E(2,3)$ & 228 & $19.5 \pm 0.6^{b}$ \\
\hline
\end{tabular}

[a] Average of three independent experiments. [b]Average of two independent experiments.

$$
\text { Time }\left(10^{3} \mathrm{~s}\right) \quad \text { Restoring force }(\mathrm{pN})
$$

Fig. 2 Representative first-order plots of the reductive elimination of $(P-$ P)PtAr 2 complexes (left). Plot of first-order rate constants versus ligand restoring force (right).

We analyzed the trend in the reactivity across the series of the complexes in terms of the ensemble-average restoring 
forces of the biphen $\mathrm{O} \cdots \mathrm{O}_{\text {biphen }}$ coordinate (Fig. 1) calculated in free ligands (Table 1) at B3LYP/6-311+G(d) in the gas phase using a previously validated approach. ${ }^{36,67}$ Calculations of ensemble-average forces in the (P-P)PtAr2 complexes were precluded by the large size of the complexes. We confirmed that for individual conformers of the stiff-stilbene ligands, the estimated restoring force of the biphen $\mathrm{O}$-. O biphen $_{\text {coordinate }}$ varied by $<20 \mathrm{pN}$ in free and metallated ligand (Table S11). This invariance of the force to the coordination environment validates the use of the restoring forces derived from free ligands as proxies of the force responsible for the variations in the elimination kinetics across the series of the (P-P)PtAr 2 complexes.

Compression forces decrease the rate of reductive elimination whereas extension forces increase the rate of reductive elimination, with a 3.4-fold variation in reaction rate across a $\sim 290 \mathrm{pN}$ change in applied force (Table 1, Fig. 2). This trend is qualitatively consistent with prior observations that larger bite angle phosphines are known to accelerate reductive elimination, ${ }^{71-74}$ and with the calculated structure of the transition state of a related reaction. ${ }^{75-79}$

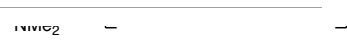

$\mathrm{NMe}_{2}$

Scheme 2 Concerted reductive elimination from platinum diaryl bisphosphine complexes.

The well-established elementary nature of reductive elimination from diaryl platinum bis(phosphine) complexes ${ }^{56-62}$ (i.e., free from dynamic structural rearrangements ${ }^{56,59-62}$ ) (Scheme 2) facilitates quantitative molecular interpretation of force/rate correlations in the reductive elimination of (P-P)PtAr 2 complexes. The observed correlations appear to arise predominately from one of the two mechanistic extremes shown in Fig. 3.80,81 At one extreme, the effect reflects distortions of the complex geometry, for example an opening of the P-Pt-P bond angle and/or elongation of the Pt-P bonds by tensile force (Fig. 3a). Such distorted geometries are reminiscent of entatic states of bioinorganic chemistry, with the altered catalytic activity arising from the changed sterics of the active site or the relative energies and shapes of molecular orbitals that participate in catalytic reactions. ${ }^{82}$ In this extreme, the transition state geometry has little effect on how the reaction rate depends on the applied force. For the present reaction, the relatively invariant one-bond platinum-phosphorous coupling constants $\left({ }^{1} J_{\mathrm{P}-\mathrm{Pt}}\right)$ demonstrate that geometry of the first coordination sphere of Pt is insensitive to force.
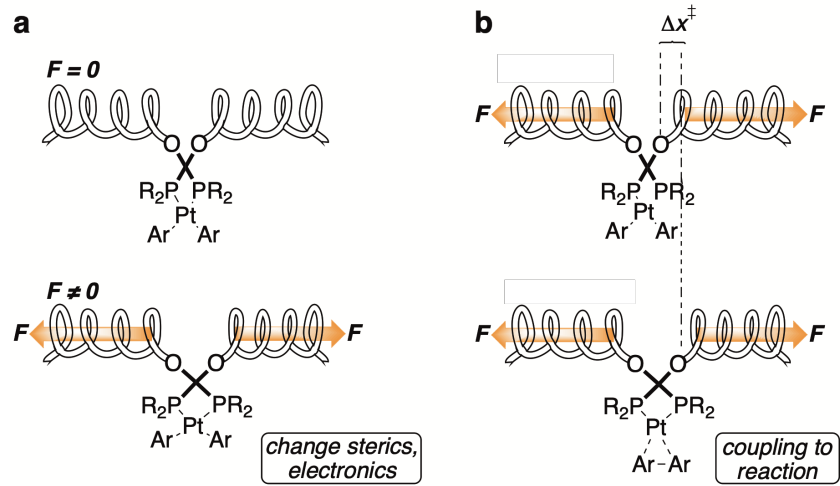

Fig. 3 Force applied to a ligand (as depicted here by a coupled spring) can influence reactivity of the metal complex through two different effects: (a) mechanical force can distort the geometry of the complex and its associated electronic energy in the force-coupled state (bottom) relative to the forcefree state (top), and/or (b) coupling to the motions of the reactant (top) as the structure shifts to that of the transition state (bottom).

Instead, the other extreme is likely operative here. The force-dependent changes in the activation barriers reflect changes in the strain energy of the molecular coordinates defined by atoms whose bonding does not change during the reaction (represented as a spring in Fig. 3). Under tensile force, the elongation of the biphen $\mathrm{O} \cdots \mathrm{O}_{\text {biphen }}$ distance in the transition state allows partial relaxation of the stretched springs, lowering their strain energy and hence the energy of the transition state relative to the reactant (Fig. 3b). In the simplest case, $\Delta G^{\ddagger}(f)=\Delta G^{\ddagger}$ o $f \bullet \Delta x^{\ddagger}$, 33 where $\Delta x^{\ddagger}$ is the change in the internuclear distance whose restoring force is $f$, between the rate-determining transition state and reactant. This results in a force-dependent rate constant, $k$, that varies as $\ln (k) \sim f$, which is indeed observed for the rate constants measured in the (P-P) $\mathrm{PtAr}_{2}$ complexes (Fig. 4).

Fig. 4 The natural log of rate constants $\left(10^{-5} \mathrm{~s}^{-1}\right)$ of reductive elimination $(k)$ as a function of applied force to the ligand.

The slope of the plot in Fig. 4 suggests an elongation of the biphen $\mathrm{O} \cdots \mathrm{O}_{\text {biphen }}$ distance at the transition state relative to the reactant complex by $0.23 \pm 0.02 \AA$. Across all ligand conformers, the biphen $\mathrm{O} \cdots \mathrm{O}_{\text {biphen }}$ and $\mathrm{P}$...P distances are linearly correlated with coefficient of 0.92 , suggesting $\sim 0.25 \AA$ elongation of the P...P distance in the transition state. This elongation is consistent with previous calculations by Borden and co-workers of reductive elimination from bis(triphenylphosphine)Pt(II) complexes increasing the P...P distance from $3.71 \AA$ in the reactant to $3.94 \AA$ in the transition state. ${ }^{79}$ In cases where ground state distortion effects are negligible, therefore, the study of force-coupled reaction processes in transition metal complexes might hold considerable promise as a fairly sensitive probe of transition state geometry. 
It is productive to contrast the effect of force on the reaction kinetics reported here with the historically important analysis of the effects of the bite angle of chelating bisphosphine ligands on the reactivity of transition metal complexes in the context of perturbations of the P-M-P angle. ${ }^{84-86}$ The concepts of natural bite angle and ligand flexibility developed by Casey acknowledge the potential modulation of the reactivity of a transition metal complex by a bisphosphine ligand in a manner distinct from perturbations of the P-M-P angle in the nascent complex. ${ }^{87}$, 88 The framework and results presented here extend these concepts and demonstrate that coupling of mechanical force imposed on the bisphosphine backbone measurably changes reactivity of the metal center even in the absence of discernable changes in ground state metal-ligand geometry. The change in reactivity observed here is attributed to a structural perturbation that occurs beyond the catalyst active site: the P-Pt-P angle within the complex (as reported by the one-bond coupling constant) does not change, but the molecular strain outside the active site does. The reactivity is driven by the relaxation of the outer-sphere strain in the transition state relative to the ground state.

\section{Conclusions}

We have shown that application of mechanical forces on the order of $\sim 100 \mathrm{pN}$ to an intact bisphosphine ligand scaffold produces measurable changes in the rate of reductive elimination from platinum diaryl complexes. This force-rate response is attributed to the coupling of force to the elongation of the P...P distance in the transition state for reductive elimination relative to the ground state. Although the force-rate response disclosed here is modest, these observations are both mechanistically and practically significant.We speculate that these results augur well for the viability of multi-state catalysts that are switched by mechanical force. Transition metal-catalyzed processes typically comprise a number of discrete elementary transformations, and these elementary steps are often affected differentially by ligand geometry. ${ }^{84-86}$ For example, reductive elimination often closes catalytic cycles initiated by oxidative addition, these two transformations often display opposing responses to ligand bite angle perturbations.71-74,84-86, 89, 90 In such cases, the most effective catalyst likely represents a compromise among the various microscopic steps. ${ }^{84-86,91-94}$ For this reason, catalytic systems that could be reversibly switched between active catalyst states optimized for specific steps within the catalytic cycle on the timescale of catalytic turnover ${ }^{95}$ or polymer enchainment ${ }^{96,97}$ have the potential to circumvent the inherent compromise associated with geometrically static transition metal catalysts. Mechanical force represents an attractive yet largely unexplored energy input for catalyst switching between multiple active states. ${ }^{98}$ To that end, forces on the order of $\sim 100 \mathrm{pN}$ similar to those employed here have been shown to be attainable reversibly and repeatably in elastomers under tension, ${ }^{54}$ including in a range of soft devices that respond to a variety of triggers. ${ }^{99}$, 100

The use of molecular design to impose controlled, intramolecular forces, as employed here, might also be useful for elucidating aspects of mechanistic pathways that are otherwise difficult to probe experimentally. A coupled force can be used to quantify structural changes between reactant and transition state, in much the same way that one would apply a substituent effect in a linear free energy relationship to quantify changes in charge distribution or a kinetic isotope effect to quantify changes in bonding. Complexes that involve a minimal initial structural perturbation and are chosen to ensure a consistent mechanism across a range of forces are particularly well suited for such applications. Further development along these lines should provide mechanistic insights into other organometallic transformations in ways that complement traditional mechanistic studies.

Finally, the mechanistic picture and structural analysis presented here suggests a pathway toward ligand scaffolds that are increasingly sensitive to mechanical force, namely by increasing the force-sensitivity of distortions in the natural bite angle of the ligand in a manner that taps into the concepts set forth by Casey. ${ }^{87,} 88$ In the current system, the free ligand is distorted by force more than the metallated complex, which suggests geometric confinement due to strong and highly directional metal-ligand binding. But there might also be contributions from the fact that the phosphorous cleft of the biphep ligand is sterically congested and may be somewhat difficult to deform. More deformable ligand designs might therefore offer opportunities to further influence reactivity through direct distortions of P-Pt-P bonding. We posit that less crowded phosphines, and/or more pliable metal-phosphine bonds, in the binding cleft should result in a more efficient transfer of strain from the oxygen atoms to which force is applied into the metal binding site.

\section{Conflicts of interest}

There are no conflicts to declare.

\section{Acknowledgements}

This material is based upon work supported by the U.S. Department of Energy, Office of Science, Office of Basic Energy Sciences program under Award Number DE-SC0018188 and used 
the Extreme Science and Engineering Discovery Environment (XSEDE), which is supported by National Science Foundation grant number $\mathrm{ACl}-1548562$, with computational resources provided by the SDSC under allocation TG-CHE140039. Acknowledgment is made to the Donors of the American Chemical Society Petroleum Research Fund for partial support of this research under grants 58885-ND7. Computations reported here relied on work partially supported by the Engineering and Physical Sciences Research Council under grant EP/L000075/1. We thank Dr. Benjamin Bobay (Duke University) for assistance with NMR spectroscopy.

\section{References}

1. N. Willis-Fox, E. Rognin, T. A. Aljohani and R. Daly, Chem, 2018, 4, 2499-2537.

2. S. Akbulatov and R. Boulatov, ChemPhysChem, 2017, 18, 1422-1450.

3. E. Izak-Nau, D. Campagna, C. Baumann and R. Göstl, Polymer Chemistry, 2020, 11, 2274-2299.

4. S. Jung and H. J. Yoon, Angew. Chem. Int. Ed., 2020, 59, 4883-4887.

5. X. Hu, T. Zeng, C. C. Husic and M. J. Robb, J. Am. Chem. Soc., 2019, 141, 15018-15023.

6. Y. Lin, T. B. Kouznetsova and S. L. Craig, J. Am. Chem. Soc., 2019, 142, 99-103.

7. Y. Sagara, M. Karman, E. Verde-Sesto, K. Matsuo, Y. Kim, N. Tamaoki and C. Weder, J. Am. Chem. Soc., 2018, 140, 1584-1587.

8. T. A. Kim, M. J. Robb, J. S. Moore, S. R. White and N. R. Sottos, Macromolecules, 2018, 51, 9177-9183.

9. Y. Lin, M. H. Barbee, C.-C. Chang and S. L. Craig, J. Am. Chem. Soc., 2018, 140, 15969-15975.

10. D. Yildiz, C. Baumann, A. Mikosch, A. J. C. Kuehne, A. Herrmann and R. Göstl, Angew. Chem. Int. Ed., 2019, 58, 12919-12923.

11. T. Kosuge, X. Zhu, V. M. Lau, D. Aoki, T. J. Martinez, J. S. Moore and H. Otsuka, J. Am. Chem. Soc., 2019, 141, 18981902.

12. T. Matsuda, R. Kawakami, R. Namba, T. Nakajima and J. P. Gong, Science, 2019, 363, 504-508.

13. W. Huang, X. Wu, X. Gao, Y. Yu, H. Lei, Z. Zhu, Y. Shi, Y. Chen, M. Qin, W. Wang and Y. Cao, Nat. Chem., 2019, 11, 310-319.

14. Y. Lin, T. B. Kouznetsova and S. L. Craig, J. Am. Chem. Soc., 2020, 142, 2105-2109.

15. T.-G. Hsu, J. Zhou, H.-W. Su, B. R. Schrage, C. J. Ziegler and J. Wang, J. Am. Chem. Soc., 2020, 142, 2100-2104.

16. H. Zhang, D. Zeng, Y. Pan, Y. Chen, Y. Ruan, Y. Xu, R. Boulatov, C. Creton and W. Weng, Chem. Sci., 2019, 10, 8367-8373.

17. M. K. Beyer, J. Chem. Phys., 2000, 112, 7307-7312.

18. K. L. Berkowski, S. L. Potisek, C. R. Hickenboth and J. S. Moore, Macromolecules, 2005, 38, 8975-8978.

$19 . \quad B$. Lee, Z. Niu, J. Wang, C. Slebodnick and S. L. Craig, J. Am. Chem. Soc., 2015, 137, 10826-10832.

20. J. Ribas-Arino, M. Shiga and D. Marx, Chem. Eur. J., 2009, 15, 13331-13335.
21. S. S. M. Konda, J. N. Brantley, B. T. Varghese, K. M. Wiggins, C. W. Bielawski and D. E. Makarov, J. Am. Chem. Soc., 2013, 135, 12722-12729.

22. R. Groote, B. M. Szyja, F. A. Leibfarth, C. J. Hawker, N. L. Doltsinis and R. P. Sijbesma, Macromolecules, 2014, 47, 1187-1192.

23. G. R. Gossweiler, T. B. Kouznetsova and S. L. Craig, J. Am. Chem. Soc., 2015, 137, 6148-6151.

24. M. J. Jacobs, G. Schneider and K. G. Blank, Angew. Chem. Int. Ed., 2016, 55, 2899-2902.

25. C. R. Hickenboth, J. S. Moore, S. R. White, N. R. Sottos, J. Baudry and S. R. Wilson, Nature, 2007, 446, 423-427.

26. M. T. Ong, J. Leiding, H. Tao, A. M. Virshup and T. J. Martínez, J. Am. Chem. Soc., 2009, 131, 6377-6379.

27. J. Wang, T. B. Kouznetsova, Z. Niu, M. T. Ong, H. M. Klukovich, A. L. Rheingold, T. J. Martinez and S. L. Craig, Nat. Chem., 2015, 7, 323-327.

28. J. Wang, T. B. Kouznetsova, Z. S. Kean, L. Fan, B. D. Mar, T. J. Martínez and S. L. Craig, J. Am. Chem. Soc., 2014, 136, 15162-15165.

29. J. Wang, T. B. Kouznetsova and S. L. Craig, J. Am. Chem. Soc., 2015, 137, 11554-11557.

30. M. Zhang and G. De Bo, J. Am. Chem. Soc., 2019, 141, 15879-15883.

31. M. Zhang and G. De Bo, J. Am. Chem. Soc., 2020, 142, 5029-5033.

32. R. Stevenson, M. Zhang and G. De Bo, Polymer Chemistry, 2020, 11, 2864-2868.

33. J. Yang, M. Horst, J. A. H. Romaniuk, Z. Jin, L. Cegelski and Y. Xia, J. Am. Chem. Soc., 2019, 141, 6479-6483.

34. Z. Chen, X. Zhu, J. Yang, J. A. M. Mercer, N. Z. Burns, T. J. Martinez and Y. Xia, Nat. Chem., 2020, 12, 302-309.

35. M. B. Larsen and A. J. Boydston, J. Am. Chem. Soc., 2013, 135, 8189-8192.

36. S. Akbulatov, Y. Tian, Z. Huang, T. J. Kucharski, Q.-Z. Yang and R. Boulatov, Science, 2017, 357, 299-303.

37. M. Conti, G. Falini and B. Samorì, Angew. Chem. Int. Ed., 2000, 39, 215-218.

38. J. M. J. Paulusse and R. P. Sijbesma, Angew. Chem. Int. Ed., 2004, 43, 4460-4462.

39. J. M. J. Paulusse and R. P. Sijbesma, Chem. Commun., 2008, DOI: 10.1039/b806978f, 4416.

40. F. R. Kersey, W. C. Yount and S. L. Craig, J. Am. Chem. Soc., 2006, 128, 3886-3887.

41. A. Piermattei, S. Karthikeyan and R. P. Sijbesma, Nat. Chem., 2009, 1, 133-137.

42. R. T. M. Jakobs and R. P. Sijbesma, Organometallics, 2012, 31, 2476-2481.

43. P. Michael and W. H. Binder, Angew. Chem. Int. Ed., 2015, 54, 13918-13922.

44. D. W. R. Balkenende, S. Coulibaly, S. Balog, Y. C. Simon, G. L. Fiore and C. Weder, J. Am. Chem. Soc., 2014, 136, 10493-10498.

45. M. Di Giannantonio, M. A. Ayer, E. Verde-Sesto, M. Lattuada, C. Weder and K. M. Fromm, Angew. Chem. Int. Ed., 2018, 57, 11445-11450.

46. Y. Sha, Y. Zhang, E. Xu, Z. Wang, T. Zhu, S. L. Craig and C. Tang, ACS Macro Lett., 2018, 7, 1174-1179. 
47. Y. Sha, Y. Zhang, E. Xu, C. W. McAlister, T. Zhu, Stephen L. Craig and C. Tang, Chem. Sci., 2019, 10, 4959-4965.

48. Z. S. Kean, S. Akbulatov, Y. Tian, R. A. Widenhoefer, R. Boulatov and S. L. Craig, Angew. Chem. Int. Ed., 2014, 53, 14508-14511.

49. U. Lüning, Angew. Chem. Int. Ed., 2012, 51, 8163-8165.

50. V. Blanco, D. A. Leigh and V. Marcos, Chem. Soc. Rev., 2015, 44, 5341-5370.

51. A. J. Teator, D. N. Lastovickova and C. W. Bielawski, Chem. Rev., 2015, 116, 1969-1992.

52. J. Choudhury, Tetrahedron Lett., 2018, 59, 487-495.

53. C. Chen, ACS Catalysis, 2018, 8, 5506-5514.

54. Z. Huang and R. Boulatov, Chem. Soc. Rev., 2011, 40, 2359.

55. A. de Meijere, S. Bräse and M. Oestreich, MetalCatalyzed Cross-Coupling Reactions and More, 3 Vol. Set, Wiley-VCH, Weinheim, 2014.

56. S. Shekhar and J. F. Hartwig, J. Am. Chem. Soc., 2004, 126, 13016-13027.

57. J. M. Brown, J. J. Perez-Torrente and N. W. Alcock, Organometallics, 1995, 14, 1195-1203.

58. T. J. Colacot, R. A. Teichman, R. Cea-Olivares, J. G. Alvarado-Rodríguez, R. A. Toscano and W. J. Boyko, J. Organomet. Chem., 1998, 557, 169-179.

59. P. S. Braterman, R. J. Cross and G. B. Young, J. Chem. Soc., Dalton Trans., 1977, DOI: 10.1039/dt9770001892, 1892.

60. H. A. Brune and J. Ertl, Liebigs Ann. Chem., 1980, 1980, 928-937.

61. R. K. Merwin, R. C. Schnabel, J. D. Koola and D. M. Roddick, Organometallics, 1992, 11, 2972-2978.

62. T. Korenaga, K. Abe, A. Ko, R. Maenishi and T. Sakai, Organometallics, 2010, 29, 4025-4035.

63. D. Villarón and S. J. Wezenberg, Angew. Chem. Int. Ed., 2020, DOI: 10.1002/anie.202001031.

64. R. Boulatov, Nat. Chem., 2012, 5, 84-86.

65. S. L. Craig, Nature, 2012, 487, 176-177.

66. H. Zhang, X. Li, Y. Lin, F. Gao, Z. Tang, P. Su, W. Zhang, Y. Xu, W. Weng and R. Boulatov, Nat. Commun., 2017, 8, 1147.

67. S. Akbulatov, Y. Tian and R. Boulatov, J. Am. Chem. Soc., 2012, 134, 7620-7623.

68. C. A. Tolman, Chem. Rev., 1977, 77, 313-348.

69. G. K. Anderson, J. A. Davies and D. J. Schoeck, Inorg. Chim. Acta, 1983, 76, L251-L252.

70 B. Z. Momeni, H. Kazmi and A. Najafi, Helv. Chim. Acta, 2011, 94, 1618-1627.

71. J. M. Brown and P. J. Guiry, Inorg. Chim. Acta, 1994, 220, 249-259.

72. J. M. Brown and N. A. Cooley, Organometallics, 1990, 9, 353-359.

73. T. Kohara, T. Yamamoto and A. Yamamoto, J. Organomet. Chem., 1980, 192, 265-274.

74. J. E. Marcone and K. G. Moloy, J. Am. Chem. Soc., 1998, 120, 8527-8528.

75. J. J. Low and W. A. Goddard, Organometallics, 1986, 5, 609-622.

76. A. C. Balazs, K. H. Johnson and G. M. Whitesides, Inorganic Chemistry, 1982, 21, 2162-2174.
77.

78.

K. Tatsumi, R. Hoffmann, A. Yamamoto and J. K. Stille, Bull. Chem. Soc. Jpn., 1981, 54, 1857-1867.

K. L. Bartlett, K. I. Goldberg and W. T. Borden, J. Am. Chem. Soc., 2000, 122, 1456-1465.

79. K. L. Bartlett, K. I. Goldberg and W. T. Borden, Organometallics, 2001, 20, 2669-2678.

80. L. Anderson and R. Boulatov, Adv. Phys. Org. Chem., 2018, 52, 87-143.

81. Y. Tian and R. Boulatov, ChemPhysChem, 2012, 13, 22772281.

82. B. L. Vallee and R. J. Williams, Proc. Natl. Acad. Sci. U. S. A., 1968, 59, 498-505.

83.

W. Kauzmann and H. Eyring, J. Am. Chem. Soc., 1940, 62, 3113-3125.

84. P. W. N. M. van Leeuwen, P. C. J. Kamer, J. N. H. Reek and P. Dierkes, Chem. Rev., 2000, 100, 2741-2770.

85. P. Dierkes and P. W. N. M. van Leeuwen, J. Chem. Soc., Dalton Trans., 1999, DOI: 10.1039/a807799a, 1519-1530.

86. P. W. N. M. van Leeuwen, P. C. J. Kamer and J. N. H. Reek, Pure Appl. Chem., 1999, 71, 1443-1452.

87. C. P. Casey and G. T. Whiteker, Isr. J. Chem., 1990, 30, 299-304.

88. C. P. Casey, G. T. Whiteker, M. G. Melville, L. M. Petrovich, J. A. Gavney and D. R. Powell, J. Am. Chem. Soc., 1992, 114, 5535-5543.

89. P. C. J. Kamer, P. W. N. M. van Leeuwen and J. N. H. Reek, Acc. Chem. Res., 2001, 34, 895-904.

90. M. Portnoy and D. Milstein, Organometallics, 1993, 12, 1665-1673.

91. M. Kranenburg, P. C. J. Kamer and P. W. N. M. van Leeuwen, Eur. J. Inorg. Chem., 1998, 1998, 25-27.

92. T. Hayashi, M. Konishi and M. Kumada, Tetrahedron Lett., 1979, 20, 1871-1874.

93. M. Kumada, Pure Appl. Chem., 1980, 52, 669-679.

94. T. Hayashi, M. Konishi, Y. Kobori, M. Kumada, T. Higuchi and K. Hirotsu, J. Am. Chem. Soc., 1984, 106, 158-163.

95. R. S. Stoll and S. Hecht, Angew. Chem. Int. Ed., 2010, 49, 5054-5075.

96. B. P. Fors and C. J. Hawker, Angew. Chem. Int. Ed., 2012, 51, 8850-8853.

97. B. M. Neilson and C. W. Bielawski, Chem. Commun., 2013, 49, 5453.

98. J. Li, C. Nagamani and J. S. Moore, Acc. Chem. Res., 2015, 48, 2181-2190.

99. J. Park, Y. Lee, M. H. Barbee, S. Cho, S. Cho, R. Shanker, J. Kim, J. Myoung, M. P. Kim, C. Baig, S. L. Craig and H. Ko, Adv. Mater., 2019, 31, 1808148.

100. M. H. Barbee, K. Mondal, J. Z. Deng, V. Bharambe, T. V. Neumann, J. J. Adams, N. Boechler, M. D. Dickey and S. L. Craig, ACS Appl. Mater. Interfaces, 2018, 10, 2991829924. 